\title{
Glucose transporter expression differs between bovine monocyte and macrophage subsets and is influenced by milk production
}

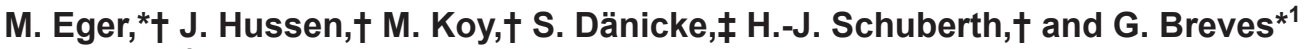 \\ *Department of Physiology, and \\ †Immunology Unit, University of Veterinary Medicine Hannover, Foundation, D-30173 Hannover, Germany \\ flnstitute of Animal Nutrition, Friedrich-Loeffler Institute, Federal Research Institute for Animal Health, D-38116 Braunschweig, Germany
}

\begin{abstract}
The peripartal period of dairy cows is characterized by negative energy balance and higher incidences of infectious diseases such as mastitis or metritis. With the onset of lactation, milk production is prioritized and large amounts of glucose are transported into the mammary gland. Decreased overall energy availability might impair the function of monocytes acting as key innate immune cells, which give rise to macrophages and dendritic cells and link innate and adaptive immunity. Information on glucose requirements of bovine immune cells is rare. Therefore, this study aims to evaluate glucose transporter expression of the 3 bovine monocyte subsets (classical, intermediate, and nonclassical monocytes) and monocyte-derived macrophages and to identify influences of the peripartal period. Blood samples were either collected from nonpregnant healthy cows or from 16 peripartal German Holstein cows at $\mathrm{d}-14,+7$, and +21 relative to parturition. Quantitative real-time PCR was applied to determine mRNA expression of glucose transporters (GLUT) 1, GLUT3, and GLUT4 in monocyte subsets and monocytederived macrophages. The low GLUT1 and GLUT3 expression in nonclassical monocytes was unaltered during differentiation into macrophages, whereas in classical and intermediate monocytes GLUT expression was downregulated. Alternatively activated M2 macrophages consumed more glucose compared with classically activated M1 macrophages. The GLUT4 mRNA was only detectable in unstimulated macrophages. Neither monocytes nor macrophages were insulin responsive. In the peripartum period, monocyte GLUT1 and GLUT3 expression and the GLUT3/GLUT1 ratio were negatively correlated with lactose production. The high-affinity GLUT3 transporter appears to be the
\end{abstract}

Received September 23, 2015.

Accepted November 11, 2015.

${ }^{1}$ Corresponding author: gerhard.breves@tiho-hannover.de predominant glucose transporter on bovine monocytes and macrophages, especially in the peripartal period when blood glucose levels decline. Glucose transporter expression in monocytes is downregulated as a function of lactose production, which might impair monocyte to macrophage differentiation.

Key words: monocyte subset, macrophage, glucose, peripartal

\section{INTRODUCTION}

Mastitis and metritis impair dairy cow profitability by reducing milk yield, fertility, and lifespan. The most critical period for infectious diseases is early lactation (Fleischer et al., 2001) when energy requirements for lactation and maintenance exceed feed energy intake and cause negative energy balance (Bell, 1995). Therefore, several studies link negative energy balance and immune suppression during the peripartal period (Hammon et al., 2006; Ohtsuka et al., 2006). With the onset of lactation, milk production is prioritized over other physiological processes and up to $80 \%$ of the available body glucose is transported into the mammary gland for the lactose synthesis (Bauman and Currie, 1980). Although lipolysis and gluconeogenesis are heightened (Drackley et al., 2001), blood glucose levels decline after parturition (Hammon et al., 2009; Galvão et al., 2010). Low blood glucose levels may contribute to immune suppression by limiting energy supply of immune cells.

Activation increases immune cell energy demands dramatically, due to a metabolic switch from oxidative phosphorylation (OXPHOS) to glycolysis. Therefore, glucose transporter expression and glucose uptake are upregulated to meet increased energy requirements (Krawczyk et al., 2010; Palmer et al., 2014). Glucose is the primary energy source of monocytes (PithonCuri et al., 2004), key innate immune cells which give rise to macrophages and link innate and adaptive immunity (Gordon and Taylor, 2005). Certain monocyte and macrophage features such as phagocytosis, IL-1 $\beta$ production, and macrophage polarization are related to glucose availability (Orlinska and Newton, 1993; 
Wong et al., 1999; Freemerman et al., 2014). Among the heterogeneous population of macrophages, the proinflammatory classically activated (M1) macrophages and the regulatory alternatively activated (M2) macrophages represent 2 well-known phenotypes that exhibit differences in glucose metabolism. Proinflammatory M1 macrophages are highly dependent on glycolysis and a shift toward a proinflammatory phenotype is inducible by glucose transporter overexpression in murine macrophages (Haschemi et al., 2012; Freemerman et al., 2014). In contrast, M2 macrophages rely more on OXPHOS or $\beta$-oxidation as an energy source (Vats et al., 2006).

In cattle, 3 monocyte subsets have been defined, classical (cM, CD14+CD16-), intermediate (intM, CD14+CD16+), and nonclassical monocytes (ncM, CD14-CD16+), which differ in phenotypic and functional properties. Whereas cM are capable to phagocyte the highest amount of bacteria and intM are the main producers of ROS, the function of bovine ncM remains largely unknown (Hussen et al., 2013). Recently we discovered that these functional differences are accompanied by differences in glucose uptake capacity of the 3 monocyte subsets (Eger et al., 2015). In humans, monocyte glucose uptake is mainly mediated by the sodium-independent glucose transporters (GLUT), GLUT1, GLUT3, and GLUT4 (Maratou et al., 2007). In murine and human macrophages, expression of GLUT1 and GLUT3 is reported (Gamelli et al., 1996; Malide et al., 1998; Ouro et al., 2013). Whereas GLUT1 is a ubiquitously expressed basal glucose transporter, the high-affinity GLUT3 is primarily expressed in neuronal tissues and GLUT4 mediates insulin-regulated glucose transport in muscle and adipose tissue (Zhao and Keating, 2007). In cattle, only one study describes mRNA and protein expression of GLUT1, GLUT3, and GLUT4 on bovine monocytes (O'Boyle et al., 2012). Data for monocyte subsets or macrophage GLUT expression are lacking. Therefore, this study aims at examining glucose transporter expression of the 3 bovine monocyte subsets and monocyte-derived macrophages and to identify influences of the peripartal period on glucose transporter expression.

\section{MATERIALS AND METHODS}

\section{Ethics Statement}

This study was approved by the Lower Saxony State Office for Customer Protection and Food Safety (33.9-42502-05-10A098, 33.9-42502-04-11/0444). All procedures involving animals were carried out in accordance with the German legislation on animal welfare.

\section{Animals}

Blood samples for separation of monocyte and macrophage subsets were collected from healthy nonpregnant, nonlactating German Holstein cows (3 to 14 yr old) housed in the Clinic for Cattle, University of Veterinary Medicine, Hannover, Germany. Effects of the peripartal period were examined using blood samples from 16 German Holstein cows housed in the experimental station of the Institute of Animal Nutrition, Friedrich-LoefflerInstitute, Braunschweig, Germany. The animals were included in a study using a feeding model for induction of subclinical ketosis. Study design, feed composition, performance, and milk parameters are described in detail in Drong et al. (2015). Briefly, the BCS of the cows was determined before the experiment and cows were allotted to a BCS low (BCS $2.77 \pm 0.14$, mean \pm SD) and a BCS high $(3.95 \pm 0.08$, mean $\pm \mathrm{SD})$ group $(\mathrm{n}=$ 14 and $n=13$, respectively; 8 cows of each group were randomly selected for PCR analysis). Body weight, milk yield, and milk composition of the previous lactation did not differ between both groups. During the experimental period from d 42 before calving until d 56 of lactation, the animals were housed in a free-stall barn with individual feeding stations. Antepartum, low BCS cows received a diet of $80 \%$ roughage ( $50 \%$ grass silage and $50 \%$ corn silage based on DM content) and $20 \%$ concentrate according to the recommendations of the German Society of Nutrition Physiology (GfE, G. S. f. N. P, 2001). The high BCS group received $40 \%$ of the same roughage and $60 \%$ concentrate to induce energy oversupply. After calving the concentrate proportion in the diet was raised from $30 \%$ to $50 \%$ in 2 or 3 wk for the low BCS and the high BCS group, respectively, to promote negative energy balance in the high BCS group. After calving, cows were milked twice per day. Milk samples were collected twice a week and analyzed for fat, protein, lactose, and urea concentrations (wk 1: $\mathrm{n}=5$; wk $3: \mathrm{n}=15$ ) using an infrared milk analyzer (Milkoscan FT 6000, Foss Electric, Hillerød, Denmark). Blood samples were collected at d -14 before predicted parturition $(d-14), d 7(d+7)$, and $d 21(d+21)$ of lactation at $0800 \mathrm{~h}$. Samples were collected by jugular venipuncture into heparinized vacutainer tubes.

\section{Magnetic Activated Cell Sorting of CD14+ Monocytes}

For magnetic activated cell sorting (MACS) peripheral blood mononuclear cells (PBMC) were isolated using density gradient separation. Blood was diluted with PBS (4:3), layered on Biocoll (density $1.077 \mathrm{~g} /$ $\mathrm{mL}$ at $20^{\circ} \mathrm{C}$, Biochrom AG, Berlin, Germany) and centrifuged at $1,000 \times g$ for $30 \mathrm{~min}$ at $10^{\circ} \mathrm{C}$. The in- 
terphase containing PBMC was collected. Remaining erythrocytes were lysed by adding $20 \mathrm{~mL}$ of Aqua destillata for $20 \mathrm{~s}$ and subsequent addition of $20 \mathrm{~mL}$ of double-concentrated PBS. Thereafter, cells were washed twice with PBS $(250 \times g, 100 \times g$ for 10 min at $10^{\circ} \mathrm{C}$ ). Cells were suspended in PBS containing $5 \mathrm{~g} / \mathrm{L}$ of BSA and $2 \mathrm{mM}$ EDTA (MACS-buffer) and cell aggregates were removed using Pre-Separation Filters (Miltenyi Biotec, Bergisch Gladbach, Germany). Viable PBMC were counted and incubated with anti-human CD14 MicroBeads (Miltenyi Biotec) in MACS-buffer for $20 \mathrm{~min}$ at $4^{\circ} \mathrm{C}$. Thereafter, cells were washed and suspended in MACS-buffer. Monocyte separation was performed using MACS LS Columns and Quadro MACS (Miltenyi Biotec) according to the manufacturer's instructions. After addition of propidium iodide, purity of viable CD14+ monocytes was assessed by flow cytometry $(94 \% \pm 2.6 \%$, Accuri C6 Flow Cytometer, Becton Dickinson GmbH, Heidelberg, Germany).

\section{Separation of Monocyte Subsets}

Monocyte subsets were isolated according to their CD14 and CD16 expression with slight modifications according to Hussen et al. (2013). Briefly, PBMC were first sorted according to their CD16 expression using a cross-reactive anti-human CD16-FITC antibody (AbD Serotec, Oxford, UK) and the Anti-FITC MultiSort Kit (Miltenyi Biotec). After release of the Anti-FITC MultiSort MicroBeads (MultiSort release reagent, Anti-FITC MultiSort Kit, Miltenyi Biotec), an additional MACS step of the CD16+ cells was performed to remove cells with remaining beads. Subsequently, CD16+ and CD16 - cells were incubated with CD14 MicroBeads (Miltenyi Biotec) and sorted based on their CD14 expression. Purity of sorted CD14+CD16- cM $(95.2 \% \pm 1.0 \%), \mathrm{CD} 14+\mathrm{CD} 16+\operatorname{intM}(81.0 \% \pm 2.6 \%)$, and CD14-CD16+ ncM $(87.1 \% \pm 2.2 \%)$ was analyzed by flow cytometry. Dead cells were excluded from the analysis by addition of propidium iodide (final concentration $2 \mu \mathrm{g} / \mathrm{mL}$, Calbiochem, Bad Soden, Germany).

\section{Cell Culture}

Cells were suspended in Iscove's modified Dulbecco's medium (Sigma-Aldrich, Munich, Germany) supplemented with $10 \%$ fetal calf serum (Biochrom AG, Berlin, Germany), 100 U/mL Penicillin/Streptomycin (Invitrogen, Karlsruhe, Germany), $4 \mathrm{~m} M$ L-glutamine (Sigma-Aldrich), and seeded in 24 -well plates $\left(5 \times 10^{5}\right.$ cells/well). CD14+ monocytes and monocyte subsets were incubated overnight at $37^{\circ} \mathrm{C}$ and $5 \% \mathrm{CO}_{2}$. To evaluate glucose uptake and GLUT expression of macrophages derived from monocyte subsets, the re- spective subset was incubated for $4 \mathrm{~d}$ to allow differentiation into classical monocyte-derived macrophages (cMdM), intermediate monocyte-derived macrophages (intMdM), and nonclassical monocyte-derived macrophages (ncMdM). For generation of classically (M1) and alternatively activated macrophages (M2), CD14+ monocytes were incubated for $4 \mathrm{~d}$. At d 3, cells were either stimulated with $100 \mathrm{ng} / \mathrm{mL}$ of LPS (LPSEB Ultrapure from E. coli strain O111:B4, InvivoGen, Toulouse, FR) and $50 \mathrm{ng} / \mathrm{mL}$ IFN- $\gamma$ (AbD Serotec) for generation of M1 macrophages or with IL-4 (50 ng/ $\mathrm{mL}$ ) and IL-13 (50 ng/mL; both Kingfisher Biotech, Saint Paul, MN) for the generation of M2 macrophages or remained untreated (M0 macrophages). Cells for quantitative real-time PCR analysis were lysed with $350 \mu \mathrm{L}$ of RLT Plus Buffer (Qiagen, Hilden, Germany) and stored at $-80^{\circ} \mathrm{C}$. Cell culture supernatants of M0, $\mathrm{M} 1$, and $\mathrm{M} 2$ macrophages were stored at $-20^{\circ} \mathrm{C}$ until photometric detection of glucose and lactate (Clinic for Cattle, University of Veterinary Medicine, Hannover, Germany).

\section{Flow Cytometric Analysis of Cell Markers on Polarized Macrophages}

Stimulated macrophages were harvested after $24 \mathrm{~h}$ by addition of $200 \mu \mathrm{L}$ of Accutase (Sigma-Aldrich) per well for $20 \mathrm{~min}$. Accutase reaction was stopped by addition of culture medium. Cells were washed $(300 \times g$, $5 \mathrm{~min}, 4^{\circ} \mathrm{C}$ ) and suspended in PBS containing $5 \mathrm{~g} / \mathrm{L}$ of BSA and $0.1 \mathrm{~g} / \mathrm{L}$ of $\mathrm{NaN}_{3}$ (membrane immunofluorescence buffer). Macrophages were seeded in 96-well plates (40,000 cells per well) and stained with the following monoclonal antibodies: mouse anti-pig CD163PE (cross-reacting with the bovine homolog) and mouse anti-bovine CD11b-FITC (both AbD Serotec) for $20 \mathrm{~min}$ in the dark. Thereafter, cells were washed with membrane immunofluorescence buffer $(300 \times g$, 5 min, $4^{\circ} \mathrm{C}$ ) and expression levels of CD163 and CD11b were detected as mean fluorescence intensity of viable macrophages after addition of propidium iodide $(2 \mu \mathrm{g} /$ $\mathrm{mL}$, Calbiochem).

\section{Quantitative PCR Analysis}

Total RNA was extracted using the RNeasy Plus Micro Kit (Qiagen) according to the manufacturer's instructions, including the elimination of contaminating genomic DNA with a DNA eliminator column. Purity and quantity of total RNA were assessed using the Epoch Microplate Spectrophotometer (Biotek Instruments GmbH, Bad Friedrichshall, Germany). Synthesis of cDNA was performed with a total RNA amount of $50 \mathrm{ng}$ (monocyte subsets and macrophages) 
Table 1. Primer sequences and concentrations for real-time PCR

\begin{tabular}{llll}
\hline Gene & $\begin{array}{l}\text { Forward (for) and reverse (rev) primer sequences } \\
\left(5^{\prime} \rightarrow 3^{\prime}\right) \text { and concentrations }(\mathrm{n} M)\end{array}$ & bp $^{1}$ & Acc. no. $^{2}$ \\
\hline GLUT1 & $\begin{array}{l}\text { for: GACTCCATCATGGGCAACCA (300) } \\
\text { rev: GGTTCTCCTCGTTGCGGTTA (300) }\end{array}$ & 139 & NM_174602.2 \\
GLUT3 & $\begin{array}{l}\text { for: GCCGCCGATAGAGGACATTT (300) } \\
\text { rev: ATGGCGAAGATCAGAGGTGC (300) }\end{array}$ & 147 & NM_174603.3 \\
GLUT4 & $\begin{array}{l}\text { for: TCTCAGGCATCAATGCGGTT (900) } \\
\text { rev: CCACCAAGAACACCGAGACT (300) }\end{array}$ & 135 & NM_174604.1 \\
\hline
\end{tabular}

${ }^{1}$ Length of amplicons in base pairs.

${ }^{2}$ GenBank accession number of nucleotide sequence used for primer generation.

or $100 \mathrm{ng}$ (CD14+ monocytes) using the SuperScript II Reverse Transcriptase and Random Primers (both Life Technologies, Darmstadt, Germany) according to the manufacturer's instructions. Subsequent quantitative PCR was conducted using the Power SYBR Green PCR Master Mix (Applied Biosystems, Darmstadt, Germany). Thermocycling was performed in a StepOnePlus Real Time PCR system (Applied Biosystems). Primer pairs for GLUT transporters were designed using PubMed Primer Blast (Table 1). Sequencing of PCR products (Seqlab GmbH, Göttingen, Germany) confirmed specific binding of the primers. The quality of amplification was verified by melt curve analysis. A dilution series $\left(10^{6}-10^{2}\right.$ copies) of complementary DNA subclones was analyzed for each gene simultaneously with the samples, and used for the determination of the relative copy numbers of individual transcripts. The amplification efficiency was calculated from the slope of the standard curve by the formula: $\mathrm{E}=10^{-1 / \text { slope }}$ for each run, and ranged between $90 \%$ and $110 \%$. Each sample was analyzed in duplicates.

\section{Glucose Uptake Measurement}

For the measurement of glucose uptake capacities of d 4 macrophages, cells were detached by addition of $200 \mu \mathrm{L}$ of Accutase (Sigma-Aldrich) per well for 20 min. Accutase reaction was stopped by addition of culture medium. Cells were divided into a control and an uptake sample and washed twice with PBS $\left(300 \times g, 5 \mathrm{~min}, 4^{\circ} \mathrm{C}\right)$. The fluorescent probe $2-(\mathrm{N}-(7-$ nitrobenz-2-oxa-1,3-diazol-4-yl)amino)-2-deoxyglucose

(2-NBDG, Life Technologies) was used for flow cytometric assessment of glucose uptake. Cells were incubated for $1 \mathrm{~h}$ at $37^{\circ} \mathrm{C}$ and $5 \% \mathrm{CO}_{2}$ with or without $30 \mu M$ 2-NBDG in a buffer containing $\mathrm{NaCl} 140 \mathrm{~m} M$, $\mathrm{KCl} 5 \mathrm{~m} M, \mathrm{MgSO}_{4} 2.5 \mathrm{~m} M$, HEPES $20 \mathrm{~m} M$, and Dglucose $5.5 \mathrm{mM}$, pH 7.4 (Dimitriadis et al., 2005); thereafter, cells were washed twice with ice-cold PBS. Glucose uptake was measured as median fluorescence intensity of 2-NBDG for at least 3,000 viable macrophages. To examine insulin effects on monocyte glucose uptake, leukocyte samples were prepared as described previously (Eger et al., 2015), and monocytes among leukocytes were then gated based on their forward and side scatter properties. The effects of insulin on monocyte or macrophage glucose uptake were tested using different concentrations (25, 50, and $100 \mathrm{mU} / \mathrm{L}$ ) of bovine insulin (Sigma-Aldrich) and a control sample. Insulin was added to the cells a few minutes before 2-NBDG administration. After $1 \mathrm{~h}$ of incubation $\left(37^{\circ} \mathrm{C}\right.$, $5 \% \mathrm{CO}_{2}$ ) cells were washed twice with ice-cold PBS and median fluorescence intensity of 2-NBDG was determined for 10,000 monocytes or macrophages after exclusion of dead cells by propidium iodide staining $(2 \mu \mathrm{g} / \mathrm{mL}$, Calbiochem).

\section{Statistics}

Statistical analysis was performed using Graph Pad Prism 6 (Graph Pad Software, San Diego, CA) and SPSS 21 (IBM, Chicago, IL). Data were checked for Gaussian distribution using the Kolmogorov-Smirnov test. Comparisons among monocyte or macrophage subsets were performed using repeated measurements ANOVA followed by Tukey post-test. Monocyte subset and subset-derived macrophage mRNA expression were compared by Student's $t$-test for paired observations. Peripartal GLUT transporter expression was analyzed using repeated measurements 2-way ANOVA (BCS and time) or one-way ANOVA (time). Relations between glucose transporter expression and production data were analyzed by Pearson or Spearman (GLUT3) correlation. Regression analysis was performed using an inverse model: $\mathrm{Y}=\mathrm{B} 0+\mathrm{B} 1 / \mathrm{X}$. Data are shown as means \pm SEM.

\section{RESULTS}

\section{Glucose Transporter mRNA Expression in Bovine Monocyte Subsets}

Expression of glucose transporters GLUT1 and GLUT3 on the 3 bovine monocyte subsets was examined 


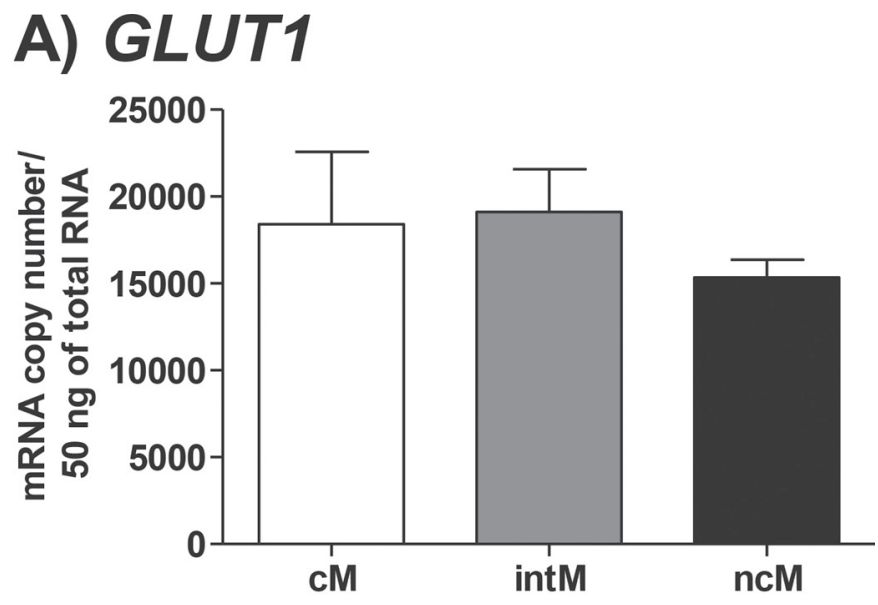

\section{B) GLUT3}

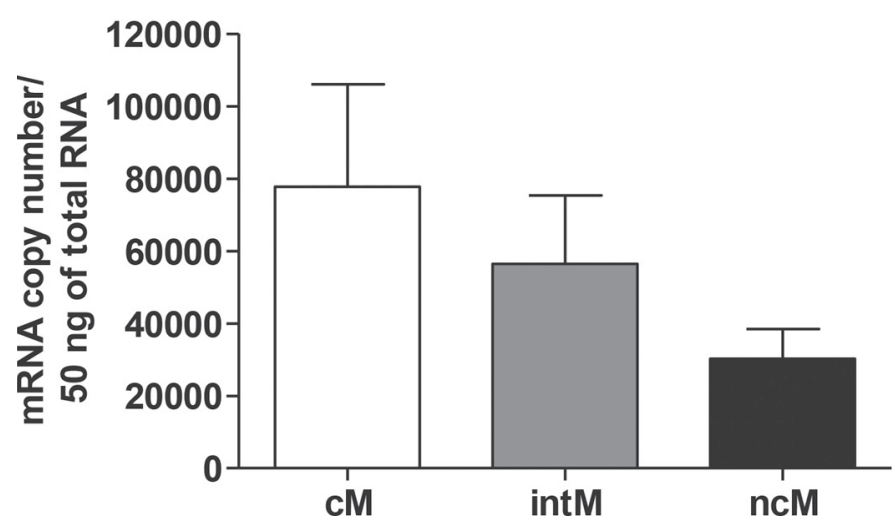

Figure 1. Glucose transporter expression in monocyte subsets. The 3 monocyte subsets, classical (cM), intermediate (intM), and nonclassical monocytes (ncM) were separated by magnetic activated cell sorting. Expression patterns of GLUT1 (A) and GLUT3 (B) mRNA were examined by quantitative real-time PCR in a total amount of $50 \mathrm{ng}$ of RNA. Effects of the factor subset on GLUT1 and GLUT3 mRNA expression were analyzed by repeated measurements ANOVA. The GLUT3 expression tended to be regulated by the factor subset $(P=$ $0.054)$. Data are shown as means $\pm \operatorname{SEM}(\mathrm{n}=5)$.

using blood samples from 5 nonpregnant, nonlactating cows. The expression of GLUT1 mRNA was similar for cM, intM, and ncM, whereas GLUT3 expression tended to decrease from $\mathrm{cM}$ to ncM $(P=0.054$, Figure 1$)$. The GLUT3 mRNA copy numbers ranged about 2- to 4 -fold higher compared with GLUT1 copy numbers for each monocyte subset.

\section{GLUT Transporter mRNA Expression Is Altered During Differentiation of Monocyte Subsets into Macrophages}

After monocyte subset-specific differentiation into macrophages ncMdM displayed a higher GLUT1 mRNA expression compared with cMdM $(P<0.05$, Figure $2 \mathrm{~A})$, whereas GLUT3 mRNA expression was lower in cMdM and intMdM compared with ncMdM $(P<0.05$, Figure 2B). Subset-derived macrophage GLUT3 expression exceeded GLUT1 expression about 3- to 4-fold. However, cMdM displayed the highest glucose uptake capacity among subset-derived macrophages, followed by intMdM and ncMdM $(P<0.001$, Figure $2 \mathrm{C})$. Whereas GLUT1 expression was not altered in ncM and ncMdM $(15,336 \pm 1,022$ and $13,519 \pm 3,911$, mean $\pm \mathrm{SEM})$, it decreased during cell culture in $\operatorname{cMdM}(P=0.012)$ and intMdM $(P=0.001)$. The GLUT3 expression tended to be lower in cMdM compared with $\mathrm{cM}(P=0.058)$.

\section{Glucose Uptake Capacity of Differentially Polarized Monocyte-Derived Macrophages}

The CD14+ monocytes from nonpregnant, nonlactating cows were differentiated to classically activated M1 and alternatively activated M2 macrophages in vitro to examine glucose uptake and glucose transporter expression of the functionally different macrophage phenotypes. Proper polarization was confirmed by different expression densities of the $\beta_{2}$-integrin CD11b and the scavenger receptor CD163 on M1 and M2 macrophages $(P=0.001, P=0.004$, Figure 3$)$. We observed the highest expression of GLUT1 and GLUT3 mRNA in M2 macrophages and lower levels in M0 and M1 macrophages $(P<0.01$, Figure 4A, 4B). The GLUT3 mRNA expression ranged about 2- to 4 -fold higher compared with GLUT1 expression for each macrophage subset. Glucose uptake of M1 macrophages was decreased compared with M2 and M0 macrophages $(P<0.05$, Figure $4 \mathrm{C})$ and glucose consumption of M2 macrophages was higher compared with M0 and M1 macrophages resulting in lower media glucose concentrations $(P<0.001$, $P<0.05$, Figure 4D), whereas lactate production did not differ among polarized macrophages (Figure 4E).

\section{Glucose Uptake of Bovine Monocytes and Macrophages Is Insulin Independent}

The GLUT4 transporter is known to act as an insulin-responsive glucose transporter. Using real-time PCR, GLUT4 mRNA was only detectable in M0 macrophages (129.4 \pm 33.7, mRNA copy number/50 ng of total RNA, mean \pm SEM, detection limit: 100 copies), not in monocyte subsets or in subset-derived macrophages. Additional in vitro glucose uptake experiments in the presence of different concentrations of insulin did not result in an increase of glucose uptake into monocytes or M0 macrophages $(\mathrm{n}=3$, Figure 5$)$. Neither a reduction of incubation time nor of temperature to 


\section{A) GLUT1}

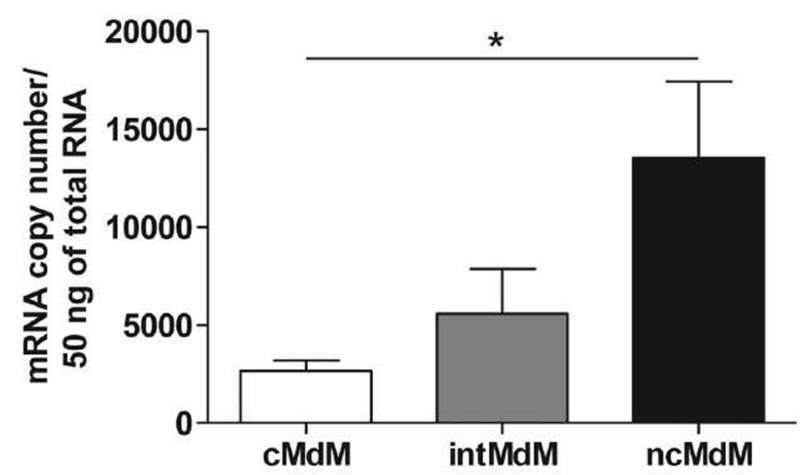

\section{B) GLUT3}

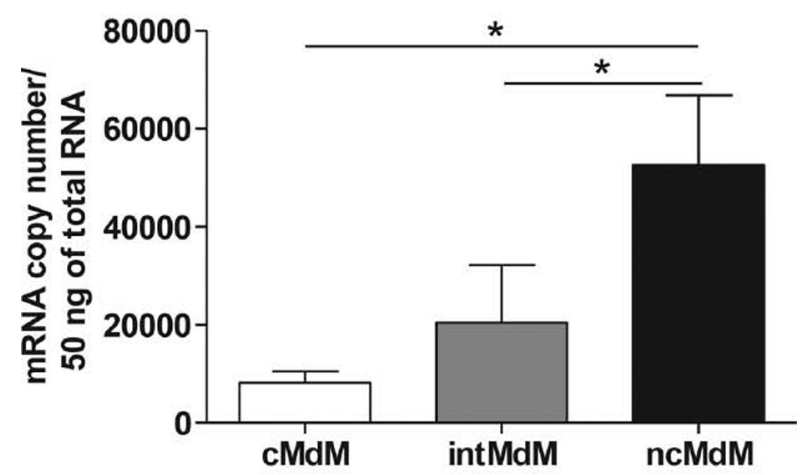

C) Glucose uptake

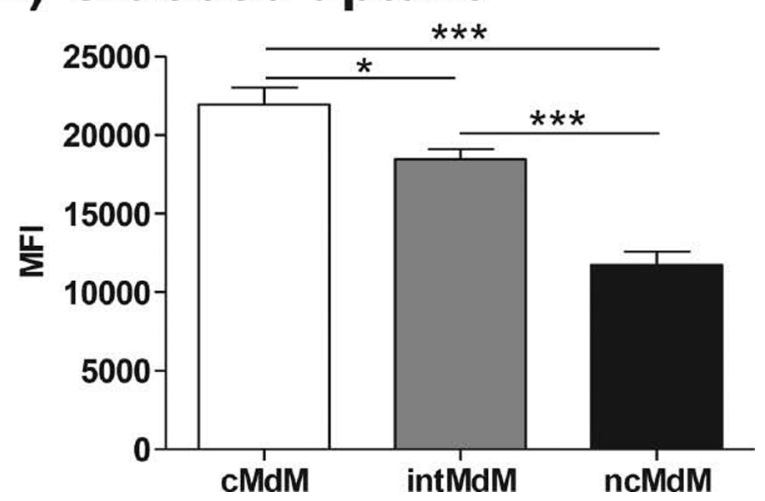

Figure 2. Glucose transporter expression and glucose uptake of monocyte subset-derived macrophages. Monocyte subsets were isolated using magnetic activated cell sorting and cultured for $4 \mathrm{~d}$ to obtain classical monocyte-derived macrophages (cMdM), intermediate monocyte-derived macrophages (intMdM), and nonclassical monocyte-derived macrophages (ncMdM). The GLUT1 (A) and GLUT3 (B) mRNA expression levels were assessed by quantitative real-time PCR. Glucose uptake capacity (C) was determined by flow cytometry as median fluorescence intensity (MFI) after $1 \mathrm{~h}$ of incubation with the fluorescent probe 2-[N-(7-nitrobenz-2-oxa-1,3-diazol-4-yl)amino]-2-deoxyglucose (2-NBDG). Repeated measurements ANOVA revealed effects of subset on macrophage GLUT1 expression $(P=0.024)$, GLUT3 expression $(P=0.011)$, and glucose uptake $(P<0.001)$. Significant differences between subset-derived macrophages in Tukey post-test are indicated by $*(P<0.05)$ or $* * *(P<0.001)$. Data are presented as means $\pm \operatorname{SEM}(\mathrm{n}=5)$.
A)
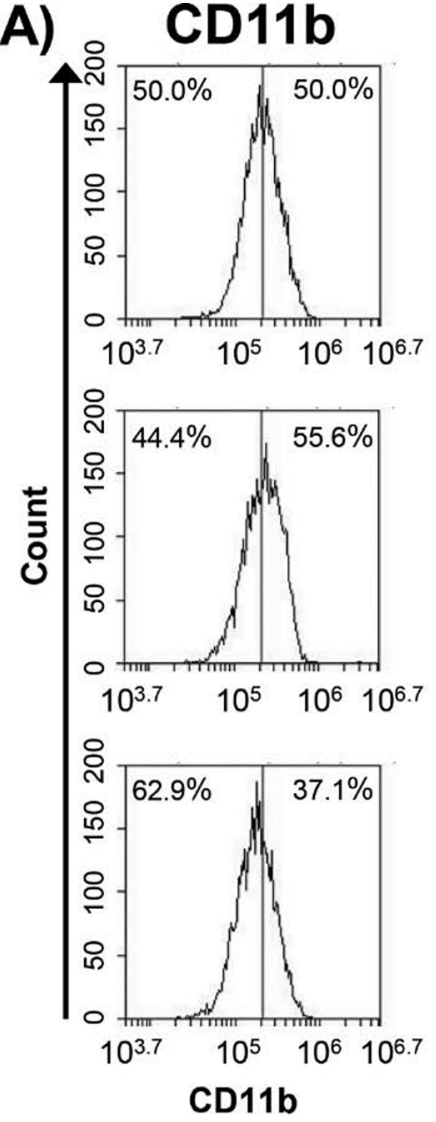

B)

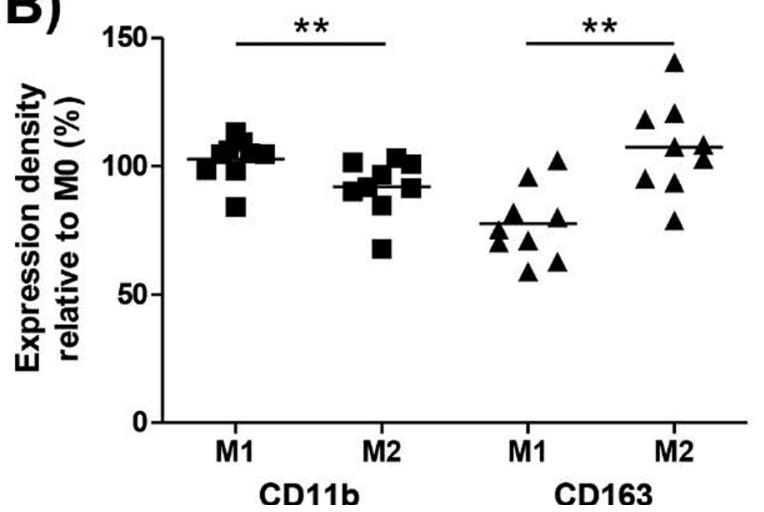

CD163

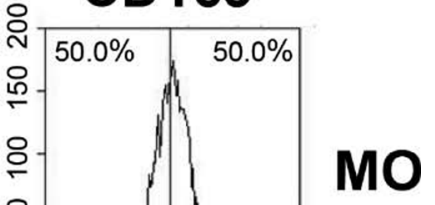

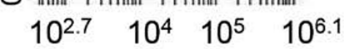
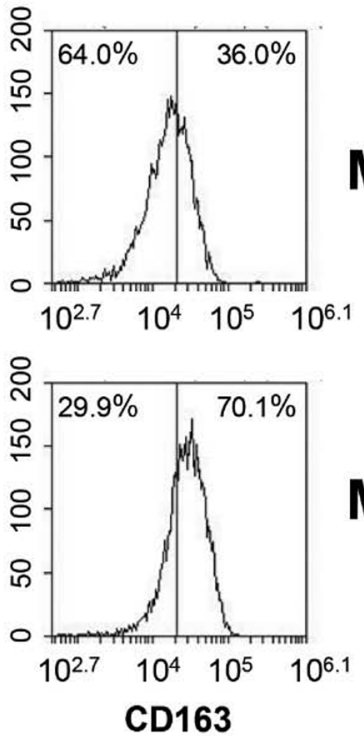

Figure 3. Polarization of macrophages. For generation of differently activated macrophages, CD14+ monocytes were separated using magnetic activated cell sorting. Cells were cultured for $4 \mathrm{~d}$ and at d 3 either stimulated with IFN- $\gamma$ and LPS for classically activated (M1) macrophages, or with IL-4 and IL-13 for alternatively activated (M2) macrophages, or remained as control (M0). Polarization of macrophages was confirmed by membrane immune fluorescence using antibodies specific for surface molecules CD11b and CD163. (A) Representative histograms of CD11b and CD163 expression on M0, M1, and M2 macrophages from one animal. The percentage of macrophages expressing the respective molecule at higher and lower density compared with the median expression of M0 macrophages (indicated by the line, CD11b: 21,539, CD163: 210,192) is given in each plot. (B) Expression of CD11b (ם) and CD163 ( $\mathbf{\Delta})$ differed significantly between M1 and M2 macrophages ( $\mathrm{n}=9, t$-test for paired observations). Expression densities are expressed in percent relative to the expression density on M0 macrophages. $* *(P<0.01)$. 
A) GLUT1

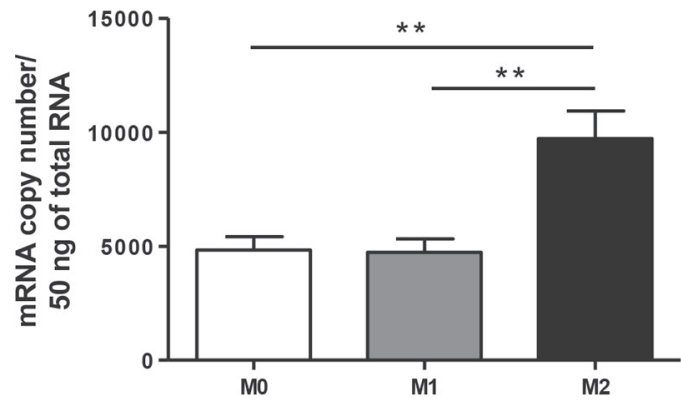

C) Glucose uptake

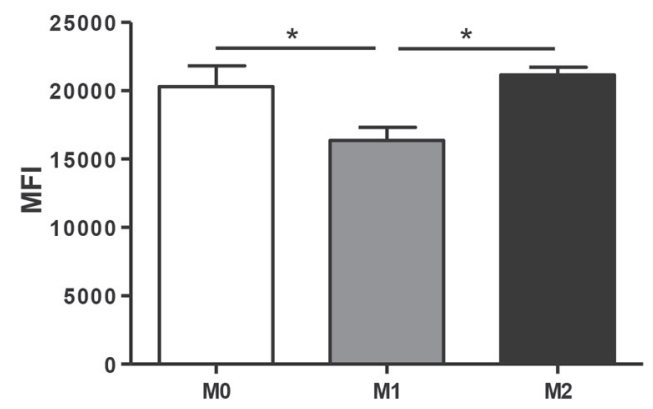

B) GLUT3

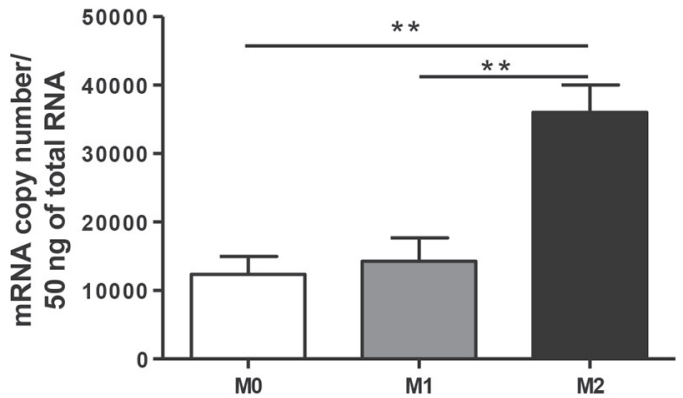

D) Glucose medium

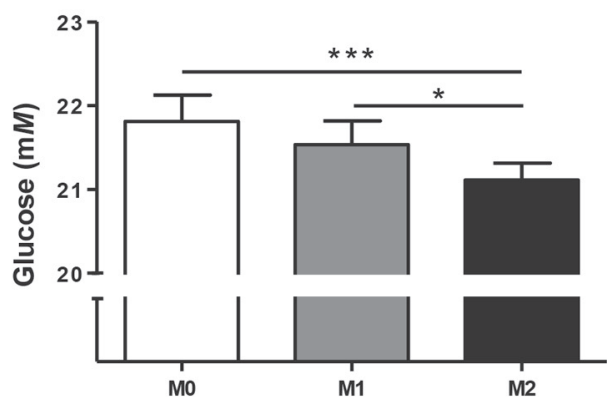

\section{E) Lactate medium}

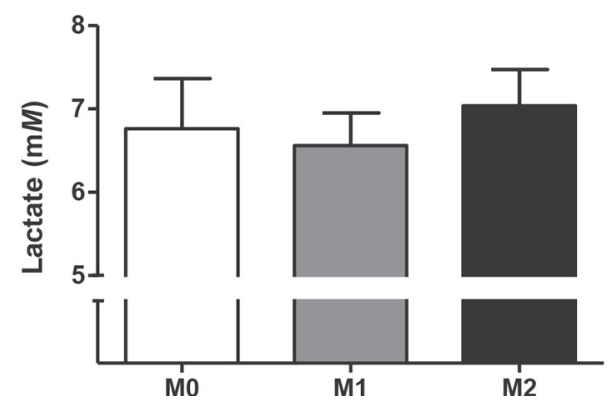

Figure 4. Glucose transporter expression and glucose consumption of polarized macrophages. At d 3 of cell culture, CD14+ monocytes were either stimulated for $24 \mathrm{~h}$ with IFN- $\gamma$ and LPS for generation of classically activated (M1) macrophages, or with IL- 4 and IL-13 for alternatively activated (M2) macrophages, or remained as control (M0). Quantitative real-time PCR was performed for assessment of GLUT1 and GLUT3 mRNA expression (A and $\mathrm{B}, \mathrm{n}=6$ ). Glucose uptake capacity $(\mathrm{C})$ was measured flow cytometrically as median fluorescence intensity (MFI) of 2-[N-(7-nitrobenz-2-oxa-1,3-diazol-4-yl)amino]-2-deoxyglucose $(2-N B D G ; n=9)$. Cell culture supernatants were analyzed for glucose and lactate concentration photometrically ( $\mathrm{D}$ and $\mathrm{E}, \mathrm{n}=9$ ). Repeated measurements ANOVA followed by Tukey post-test were applied to detect differences among polarized macrophages. Effects of macrophage polarization were observed for GLUT1 $(P=0.003)$, GLUT3 $(P<0.001)$, glucose uptake $(P=0.012)$, and media glucose concentration $(P<0.001)$. Significant differences in Tukey post-test are indicated by $*(P<0.05), * *(P<0.01)$, or $* * *(P<0.001)$. Data are presented as means \pm SEM.

avoid insulin degradation changed this result (data not shown).

\section{Peripartal GLUT Transporter Expression in Monocytes Depends on Milk Production}

As glucose availability is decreased at the onset of lactation and therefore might impair immune cell function we examined the effects of the peripartal period on glucose transporter expression of monocytes isolated from 16 peripartal cows. The expression levels of GLUT1 and GLUT3 were not altered during the peripartal period (Figure 6A, 6B) and were not significantly affected by the BCS group (data not shown). Copy numbers of GLUT4 were below the detection limit in peripartal CD14+ monocytes. The ratio between GLUT3 
and GLUT1 expression increased from d $-14(1.74 \pm$ 0.18 , mean \pm SEM $)$ until $\mathrm{d}+21(2.52 \pm 0.17, P<$ 0.001, Figure 6C). Correlation analysis was performed for monocyte GLUT transporter expression and blood glucose and insulin concentrations and energy balance as relevant indicators of energy metabolism in early lactation and milk production data [milk yield, FCM, lactose (\%), lactose $(\mathrm{kg} / \mathrm{d})$, protein (\%), protein $(\mathrm{kg} / \mathrm{d})$, fat $(\%)$, fat $(\mathrm{kg} / \mathrm{d})$, urea (ppm)] at $\mathrm{d}+7$ and +21 . The GLUT transporter expression was not correlated with blood glucose or insulin concentrations or with energy balance of the cows (data not shown). However, we observed strong negative correlations between GLUT expression and lactose $(\mathrm{kg} / \mathrm{d} ; P<0.05, \mathrm{r}>-0.50)$. A higher lactose production in wk 3 was associated with a decreased GLUT1 expression at d $+21\left(\mathrm{R}^{2}=0.314\right.$, $\mathrm{B} 0=-30,557, \mathrm{~B} 1=107,794$, Figure $7 \mathrm{~A}$ ) and a higher lactose production in wk 1 resulted in a lower GLUT3 expression $\left(\mathrm{R}^{2}=0.871, \mathrm{~B} 0=-495,507, \mathrm{~B} 1=761,265\right.$, Figure 7B) and a lower GLUT3/GLUT1 ratio at d +7 $\left(\mathrm{R}^{2}=0.975, \mathrm{~B} 0=-0.432, \mathrm{~B} 1=3,549\right.$, Figure $\left.7 \mathrm{C}\right)$.

\section{DISCUSSION}

In dairy cows, the onset of lactation induces a redistribution of glucose, AA, and fatty acids toward the mammary gland (Bell, 1995). Peripartal immune suppression might therefore be linked to an insufficient energy supply to monocytes as key innate immune cells. Monocytes and macrophages primarily use glucose as energy source, to a lesser extent AA, mainly glutamine, and fatty acids (Newsholme et al., 1987; Pithon-Curi et al., 2004). Ketone bodies are not used by these cells and the effect of nonesterified fatty acids on immune function is controversial (Newsholme et al., 1987; Ingvartsen and Moyes, 2013). With the onset of lactation particularly glucose, the main energy supply of monocytes, is transported into the mammary gland at high rates (Bell, 1995). Therefore, we examined glucose transporter expression of peripartal monocytes, the 3 bovine monocyte subsets and in vitro generated macrophages. We considered macrophages derived from monocyte subsets, as well as classically activated M1 and alternatively activated M2 macrophages.

In monocyte subsets, the predominant glucose transporter detected was GLUT3. Although GLUT1 mRNA expression did not differ among monocyte subsets, GLUT3 mRNA expression in ncM was reduced. This is in agreement with the lower ability of bovine ncM to take up glucose and might be related to differences in functional properties (Hussen et al., 2013; Eger et al., 2015). The higher expression levels of GLUT3, which displays a higher affinity for glucose compared with GLUT1 (Zhao and Keating, 2007), might overlie the constant expression of GLUT1. In humans, GLUT3 is also the most important glucose transporter of monocytes on mRNA and protein level (Fu et al., 2004; Kipmen-Korgun et al., 2009); however, the only study comparing GLUT expression among human monocyte subsets examined GLUT1 expression. In contrast to the lower glucose transporter mRNA expression in bovine ncM, human ncM possess the highest protein expression of GLUT1, followed by intM and the lowest expression level is observed in cM (Palmer et al., 2014). However, glucose uptake capacities did not differ among human monocyte subsets; therefore, differences in the expres-
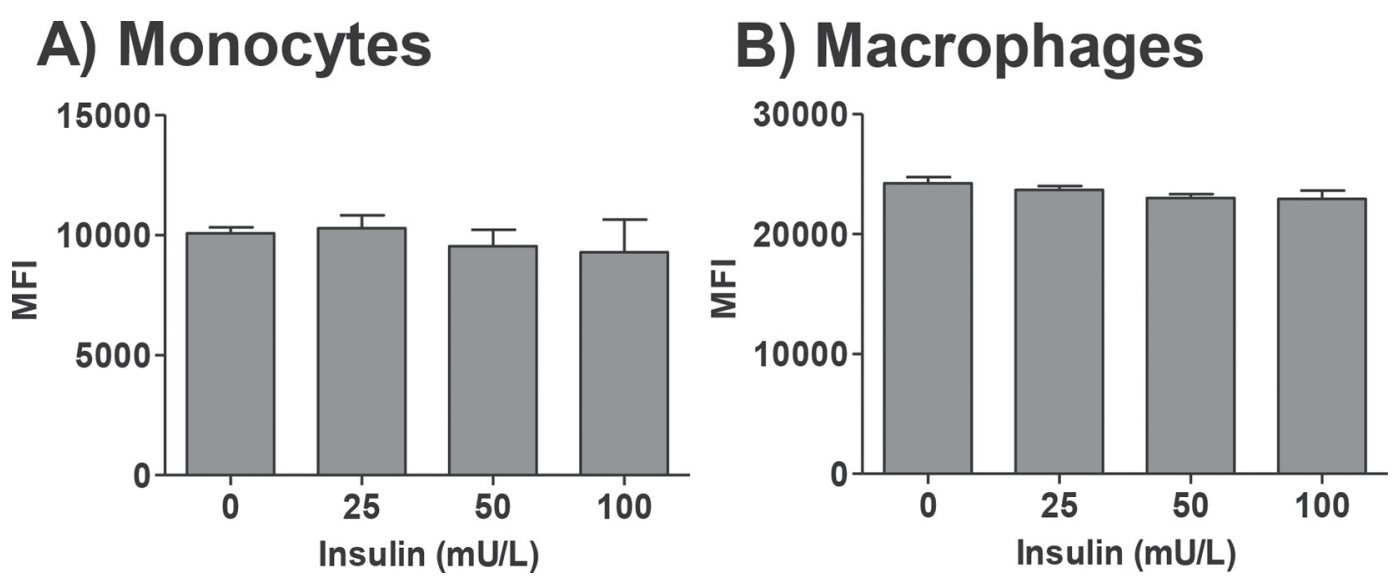

Figure 5. Glucose uptake in the presence of insulin. For testing insulin effects on monocyte (A) and macrophage (B), glucose uptake separated blood leukocytes or d 4 control (M0) macrophages derived from CD14+ monocytes were incubated with different concentrations of bovine insulin. The fluorescence probe 2-[N-(7-nitrobenz-2-oxa-1,3-diazol-4-yl)amino]-2-deoxyglucose (2-NBDG) was added for $1 \mathrm{~h}$. Glucose uptake was determined as median fluorescence intensity (MFI) of 2-NBDG by flow cytometry. Monocytes were gated among leukocytes based on their forward and side scatter properties, and at least 10,000 monocytes or macrophages were recorded for each sample. Data are presented as means $\pm \operatorname{SEM}(\mathrm{n}=3)$. 


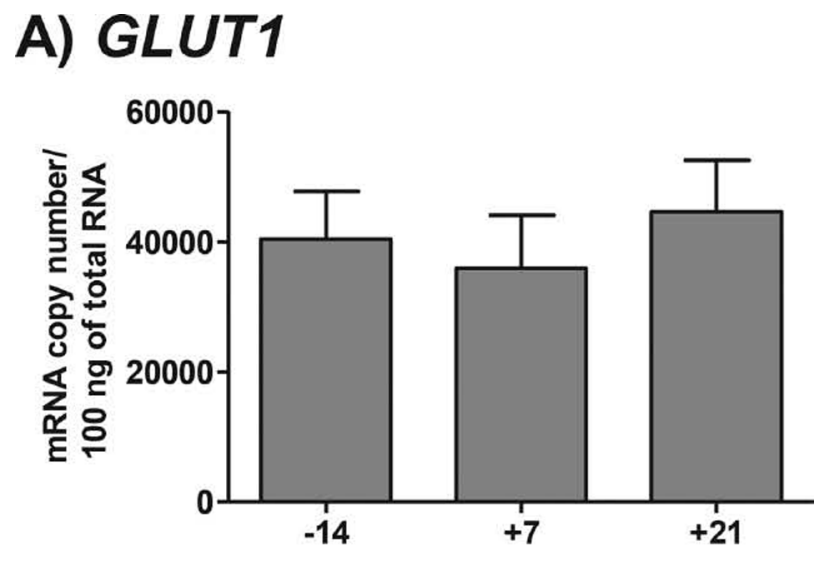

B) GLUT3

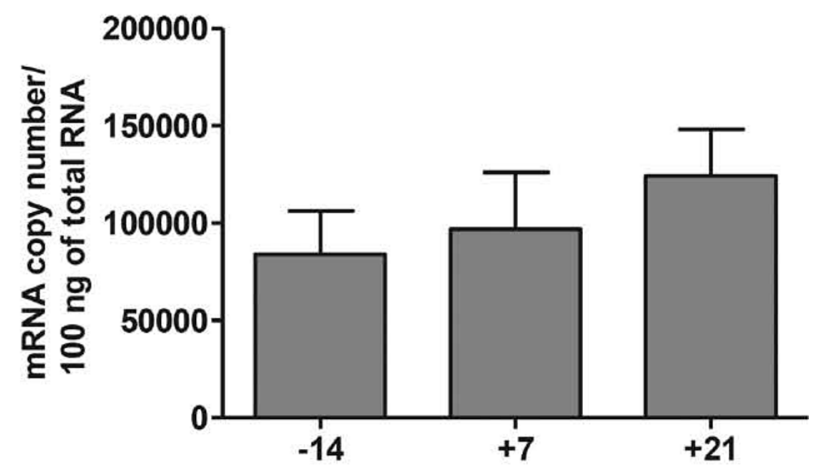

C) GLUT3/GLUT1

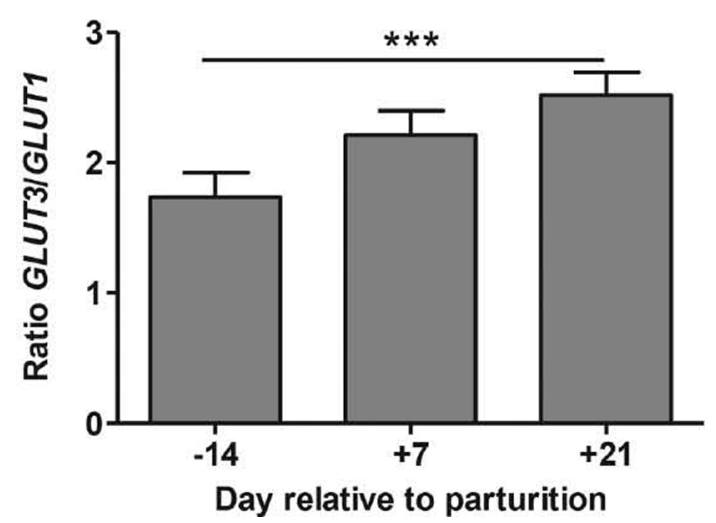

Figure 6. Glucose transporter expression in peripartal dairy cows. The CD14+ monocytes were isolated by density gradient centrifugation and subsequent magnetic activated cell sorting using blood samples from 16 German Holstein cows at $\mathrm{d}-14,+7$, and +21 relative to parturition. GLUT1 (A) and GLUT3 (B) mRNA expression was examined by quantitative real-time PCR in $100 \mathrm{ng}$ of total RNA. The ratio of GLUT3/GLUT1 mRNA expression (C) was calculated from absolute copy numbers of both transporters. Effects of the factor time were tested by repeated measurements ANOVA. Whereas no significant effects were revealed for GLUT1 and GLUT3 expression, the ratio of $G L U T 3 / G L U T 1$ increased significantly over time $(P=$ $0.001)$. Differences among time points in Tukey post-test are indicated by $* * *(P<0.001)$. Data are presented as means \pm SEM $(\mathrm{n}=16)$.

\section{A) GLUT1 day +21}

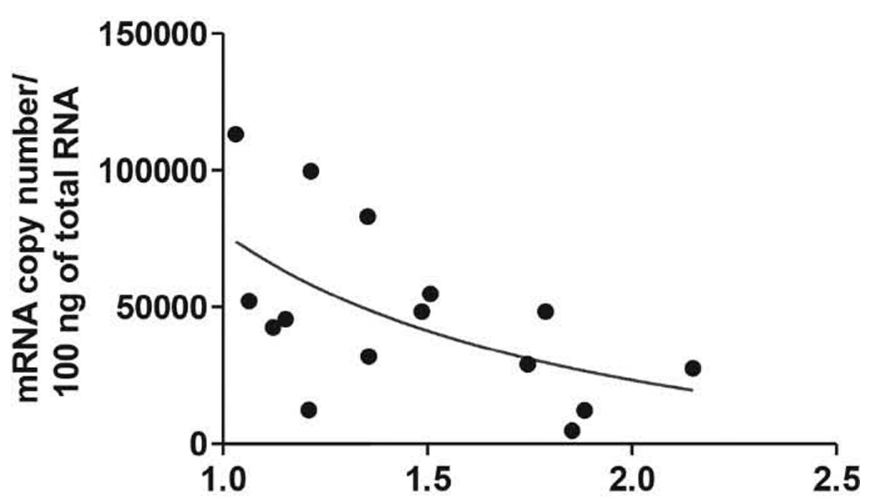

\section{B) GLUT3 day +7}

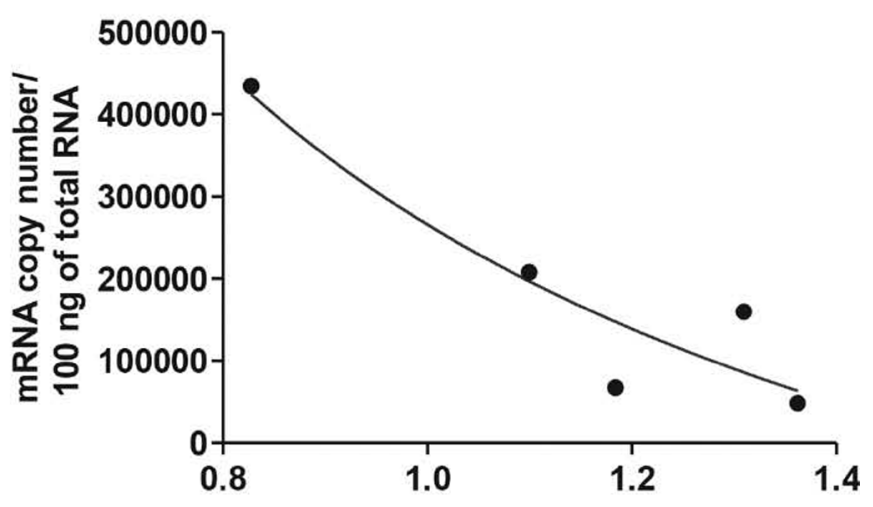

\section{C) GLUT3/GLUT1 day +7}

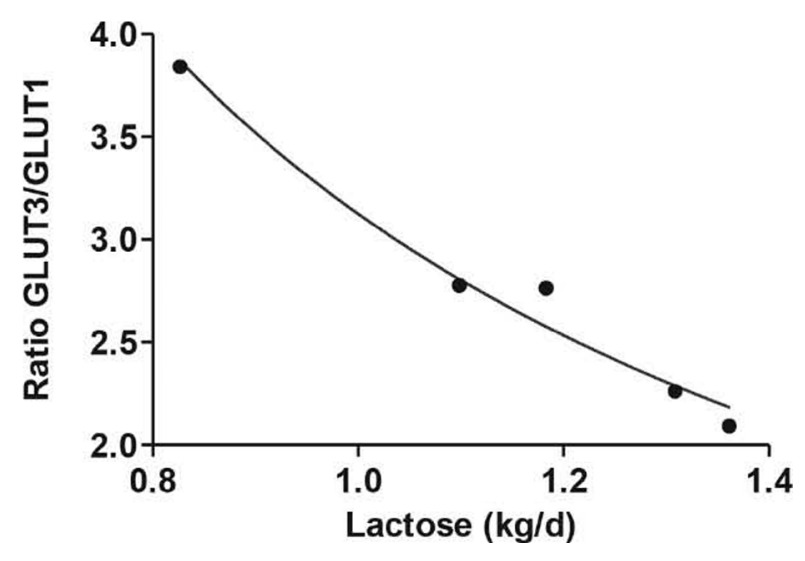

Figure 7. Peripartal monocyte glucose transporter expression is correlated with lactose production. GLUT1 (A) and GLUT3 (B) mRNA expression as well as the GLUT3/GLUT1 ratio (C) at $\mathrm{d}+7$ and $\mathrm{d}+21$ were correlated with milk production data of wk $1(\mathrm{n}=5)$ and wk 3 (n $=15$ ) of lactation, respectively, using Pearson (GLUT1 and GLUT3/ GLUT1) or Spearman (GLUT3) correlation. Significant correlations with lactose production (at least $P<0.05, \mathrm{r}>-0.50$ ) were followed by nonlinear regression analysis (inverse model: $\mathrm{Y}=\mathrm{B} 0+\mathrm{B} 1 / \mathrm{X})$. (A) GLUT1 d+21 $\left(\mathrm{R}^{2}=0.314, \mathrm{~B} 0=-30,557, \mathrm{~B} 1=107,794\right),(\mathrm{B})$ GLUT3 $\mathrm{d}+7\left(\mathrm{R}^{2}=0.871, \mathrm{~B} 0=-495,507, \mathrm{~B} 1=761,265\right)$, and $(\mathrm{C})$ GLUT3/ GLUT1 ratio d $+7\left(\mathrm{R}^{2}=0.975, \mathrm{~B} 0=-0.432, \mathrm{~B} 1=3.549\right)$. 
sion of other glucose transporters such as GLUT3 might also be present in human monocyte subsets.

After differentiation of monocyte subsets into macrophages GLUT1 mRNA expression decreased in cMdM and intMdM, whereas expression in ncMdM was unaltered and ncMdM displayed the highest GLUT1 and GLUT3 expression. In contrast, cMdM were able to take up more glucose compared with intMdM and ncMdM, resembling differences we observed for glucose uptake into monocytes subsets (Eger et al., 2015). Data about alterations of glucose transporter expression during differentiation from monocytes to macrophages are contradictory. Whereas in human THP-1 monocytes GLUT1 is downregulated and GLUT3 is upregulated on mRNA and protein level during differentiation into macrophages (Fu et al., 2004), in human blood monocyte derived macrophages GLUT1 protein expression increases and GLUT3 disappears completely during the differentiation process (Malide et al., 1998). Therefore alterations in glucose transporter expression might be cell-type specific and might differ between subsets. In humans, GLUT1 protein is redistributed during the differentiation process, from a primarily cell surface localization in monocytes to perinuclear vesicles in macrophages (Malide et al., 1998). Intracellular storage might allow maintaining high glucose uptake capacity despite of decreasing transcription and translation rates. Furthermore, differences in protein turnover or structural modifications of the transporter, such as N-glycosylation (Ahmed and Berridge, 1999), could account for the discrepancies between glucose uptake and mRNA expression.

Today several pathways of macrophage activation are established. We examined classically activated M1 macrophages, proinflammatory macrophages exhibiting antimicrobial activity, and alternatively activated M2 macrophages that regulate tissue repair and humoral immune responses (Gordon and Taylor, 2005). Compared with unstimulated M0 and to M1 macrophages, bovine M2 macrophages displayed a higher GLUT mRNA expression and glucose consumption. The lowest in vitro glucose uptake was observed for M1 macrophages. This is in contrast to murine macrophages where M1 polarization is accompanied by a high increase in glucose uptake and GLUT mRNA expression (Vats et al., 2006; Freemerman et al., 2014). The M1 macrophages primarily use the glycolysis pathway for energy generation (Rodriguez-Prados et al., 2010) and therefore require higher amounts of glucose compared with M2 macrophages which mainly use OXPHOS and fatty acid oxidation (Vats et al., 2006). However, the utilization of metabolic pathways in polarized macrophages is not exclusive. Although less pronounced, macrophage glucose uptake and glycolysis are upregulated following M2 activation (Vats et al., 2006; Haschemi et al., 2012) and Xu et al. (2015) reported an enhancement of oxidative metabolism in M1 macrophages. The increase in glucose transporter expression and glucose consumption after M2 activation we observed in bovine macrophages is consistent with these studies. The lack of GLUT or NBDG uptake upregulation in M1 macrophages might be based on metabolic properties. An immediate substrate consumption might maintain a high glucose influx through GLUT transporters due to concentration-gradient dependency of facilitated diffusion. Although polarization was confirmed by differentiation markers, the M1 stimulus might be weaker compared with the M2 stimulus and not being able to initiate metabolic changes. Preferences for glycolytic or oxidative metabolism were not recognizable by differences in lactate production; however, conversion of glucose into lactate is already very high in all macrophage types (Rodriguez-Prados et al., 2010).

Glucose transporter GLUT4 is known to mediate insulin-responsive glucose uptake in adipose tissue and skeletal muscle (Zhao and Keating, 2007). Using quantitative real-time PCR, GLUT4 was only detectable in unstimulated macrophages. However, cellular GLUT4 protein expression might differ from mRNA levels due to the fact that GLUT4 protein is stored in intracellular vesicles and may be integrated into the cell surface in response to insulin binding (Bryant et al., 2002). Therefore, we performed additional in vitro glucose uptake tests. The lack of insulin effects on glucose uptake of bovine monocytes or macrophages is in contrast to the stimulation of GLUT4 surface expression and glucose uptake triggered by insulin in human monocytes (Dimitriadis et al., 2005; Maratou et al., 2007). In contrast to our experiments, O'Boyle et al. (2012) observed expression of GLUT4 on mRNA and protein level in bovine monocytes. This might be based on differences in the methods used; however, insulin-responsiveness of the cells was not examined in the mentioned study. Due to differences in insulin sensitivity between ruminants and monogastric species (Duhlmeier et al., 2005) and peripartal insulin resistance of dairy cows (Bell and Bauman, 1997), a lack of GLUT4 expression and insulin-independency of glucose uptake might be favorable for bovine monocytes and macrophages.

After parturition, decreasing blood glucose levels might result in insufficient energy supply for monocytes; therefore, we examined glucose transporter expression in peripartal dairy cows with different dietary energy supply, which was intended to generate different levels of negative energy balance and glucose availability. However, monocyte glucose transporter mRNA expression was not influenced by the feeding group and the feeding regimen failed to generate significant differences in the 
level of negative energy balance postpartum (Drong et al., 2015). Nevertheless, the lack of correlation between energy balance or blood glucose and GLUT expression suggests that these parameters are not directly linked. Consistent with the present results, monocyte glucose uptake is not influenced by this feeding regimen either (Eger et al., 2015). In contrast, dietary energy supply affects monocyte numbers in peripartal dairy cows (Røntved et al., 2005; Eger et al., 2015). During the peripartal period, the ratio of GLUT3 to GLUT1 expression increased. A shift of glucose transporter expression toward GLUT3 might be an adaptation process to maintain a high glucose influx despite of decreasing blood glucose levels by a higher transporter affinity (Zhao and Keating, 2007). Recently we showed that monocyte in vitro glucose uptake is reduced after parturition (Eger et al., 2015). Additionally, a decrease in the mRNA expression of GLUT1 was observed in a previous study, which compared monocyte samples from about 4 to 5 wk ante partum to samples from the first week after parturition, whereas GLUT3 mRNA expression was not altered either (O'Boyle et al., 2012). Time-dependent alterations might not be visible on mRNA level in the present study due to the high influence of lactose yield on GLUT mRNA expression. We observed strong negative correlations between monocyte glucose transporter expression or the GLUT3/ GLUT1 ratio and lactose yield of the cows. Lactose is one of the most important products of mammary glucose uptake (Zhao, 2014); therefore, we suppose that monocyte glucose uptake is downregulated when mammary gland glucose uptake increases. Moreover, the reduction of the GLUT3/GLUT1 ratio indicates a decrease in the transport affinity of monocytes. A redistribution of glucose toward the mammary gland has already been reported for other organs such as adipose tissue. Whereas GLUT1 mRNA and protein expression in the mammary gland increases strongly with the onset of lactation (Komatsu et al., 2005; Finucane et al., 2008), in adipose tissue GLUT1 is decreased about 6-fold on RNA level and on protein level in early lactating cows compared with dried off or late lactating cows (Komatsu et al., 2005). The prioritization of milk production in glucose distribution also seems to affect immune cells.

The present study investigated GLUT expression in bovine monocytes and monocyte-derived macrophages to elucidate whether peripartal immune suppression in dairy cows may be evoked by low glucose supply. We provided evidence that monocyte glucose transporter expression is negatively correlated with lactose yield and is therefore directly linked to milk production of dairy cows. Monocyte or macrophage subsets with high requirements such as classical monocytes or alterna- tively activated macrophages might be particularly influenced by lactation.

\section{ACKNOWLEDGMENTS}

The financial support of Melanie Eger by the H. Wilhelm Schaumann Foundation is highly acknowledged.

\section{REFERENCES}

Ahmed, N., and M. V. Berridge. 1999. N-glycosylation of glucose transporter-1 (Glut-1) is associated with increased transporter affinity for glucose in human leukemic cells. Leuk. Res. 23:395-401.

Bauman, D. E., and W. B. Currie. 1980. Partitioning of nutrients during pregnancy and lactation: A review of mechanisms involving homeostasis and homeorhesis. J. Dairy Sci. 63:1514-1529.

Bell, A. W. 1995. Regulation of organic nutrient metabolism during transition from late pregnancy to early lactation. J. Anim. Sci. $73: 2804-2819$

Bell, A. W., and D. E. Bauman. 1997. Adaptations of glucose metabolism during pregnancy and lactation. J. Mammary Gland Biol. Neoplasia 2:265-278.

Bryant, N. J., R. Govers, and D. E. James. 2002. Regulated transport of the glucose transporter GLUT4. Nat. Rev. Mol. Cell Biol. $3: 267-277$.

Dimitriadis, G., E. Maratou, E. Boutati, K. Psarra, C. Papasteriades, and S. A. Raptis. 2005. Evaluation of glucose transport and its regulation by insulin in human monocytes using flow cytometry. Cytometry A 64:27-33.

Drackley, J. K., T. R. Overton, and G. N. Douglas. 2001. Adaptations of glucose and long-chain fatty acid metabolism in liver of dairy cows during the periparturient period. J. Dairy Sci. 84:E100-E112.

Drong, C., U. Meyer, D. von Soosten, J. Frahm, J. Rehage, G. Breves, and S. Daenicke. 2015. Effect of monensin and essential oils on performance and energy metabolism of transition dairy cows. J. Anim. Physiol. Anim. Nutr. (Berl.). http://dx.doi.org/10.1111/ jpn.12401.

Duhlmeier, R., A. Hacker, A. Widdel, W. von Engelhardt, and H. P. Sallmann. 2005. Mechanisms of insulin-dependent glucose transport into porcine and bovine skeletal muscle. Am. J. Physiol. Regul. Integr. Comp. Physiol. 289:R187-R197.

Eger, M., J. Hussen, C. Drong, U. Meyer, D. von Soosten, J. Frahm, S. Daenicke, G. Breves, and H. J. Schuberth. 2015. Impacts of parturition and body condition score on glucose uptake capacity of bovine monocyte subsets. Vet. Immunol. Immunopathol. 166:33-42.

Finucane, K. A., T. B. McFadden, J. P. Bond, J. J. Kennelly, and F. Q. Zhao. 2008. Onset of lactation in the bovine mammary gland: Gene expression profiling indicates a strong inhibition of gene expression in cell proliferation. Funct. Integr. Genomics 8:251-264.

Fleischer, P., M. Metzner, M. Beyerbach, M. Hoedemaker, and W. Klee. 2001. The relationship between milk yield and the incidence of some diseases in dairy cows. J. Dairy Sci. 84:2025-2035.

Freemerman, A. J., A. R. Johnson, G. N. Sacks, J. J. Milner, E. L. Kirk, M. A. Troester, A. N. Macintyre, P. Goraksha-Hicks, J. C. Rathmell, and L. Makowski. 2014. Metabolic reprogramming of macrophages: Glucose transporter 1 (GLUT1)-mediated glucose metabolism drives a proinflammatory phenotype. J. Biol. Chem. 289:7884-7896.

Fu, Y., L. Maianu, B. R. Melbert, and W. T. Garvey. 2004. Facilitative glucose transporter gene expression in human lymphocytes, monocytes, and macrophages: A role for GLUT isoforms 1, 3, and 5 in the immune response and foam cell formation. Blood Cells Mol. Dis. 32:182-190.

Galvão, K. N., M. J. Flaminio, S. B. Brittin, R. Sper, M. Fraga, L. Caixeta, A. Ricci, C. L. Guard, W. R. Butler, and R. O. Gilbert. 2010. Association between uterine disease and indicators of neutrophil and systemic energy status in lactating Holstein cows. J. Dairy Sci. 93:2926-2937. 
Gamelli, R. L., H. Liu, L. K. He, and C. A. Hofmann. 1996. Augmentations of glucose uptake and glucose transporter-1 in macrophages following thermal injury and sepsis in mice. J. Leukoc. Biol. 59:639-647.

GfE, G. S. f. N. P. 2001. Empfehlungen zur Energie- und Nährstoffversorgung der Milchkühe und Aufzuchtrinder (Recommendations of Energy and Nutrient Supply for Dairy Cows and Breeding Cattle). DLG Verlag, Frankfurt am Main, Germany.

Gordon, S., and P. R. Taylor. 2005. Monocyte and macrophage heterogeneity. Nat. Rev. Immunol. 5:953-964.

Hammon, D. S., I. M. Evjen, T. R. Dhiman, J. P. Goff, and J. L. Walters. 2006. Neutrophil function and energy status in Holstein cows with uterine health disorders. Vet. Immunol. Immunopathol. $113: 21-29$.

Hammon, H. M., G. Sturmer, F. Schneider, A. Tuchscherer, H. Blum, T. Engelhard, A. Genzel, R. Staufenbiel, and W. Kanitz. 2009. Performance and metabolic and endocrine changes with emphasis on glucose metabolism in high-yielding dairy cows with high and low fat content in liver after calving. J. Dairy Sci. 92:1554-1566.

Haschemi, A., P. Kosma, L. Gille, C. R. Evans, C. F. Burant, P. Starkl, B. Knapp, R. Haas, J. A. Schmid, C. Jandl, S. Amir, G. Lubec, J. Park, H. Esterbauer, M. Bilban, L. Brizuela, J. A. Pospisilik, L. E. Otterbein, and O. Wagner. 2012. The sedoheptulose kinase CARKL directs macrophage polarization through control of glucose metabolism. Cell Metab. 15:813-826.

Hussen, J., A. Duvel, O. Sandra, D. Smith, I. M. Sheldon, P. Zieger, and H. J. Schuberth. 2013. Phenotypic and functional heterogeneity of bovine blood monocytes. PLoS ONE 8:e71502.

Ingvartsen, K. L., and K. Moyes. 2013. Nutrition, immune function and health of dairy cattle. Animal 7(Suppl. 1):112-122.

Kipmen-Korgun, D., S. Bilmen-Sarikcioglu, H. Altunbas, R. Demir, and E. T. Korgun. 2009. Type-2 diabetes down-regulates glucose transporter proteins and genes of the human blood leukocytes. Scand. J. Clin. Lab. Invest. 69:350-358.

Komatsu, T., F. Itoh, S. Kushibiki, and K. Hodate. 2005. Changes in gene expression of glucose transporters in lactating and nonlactating cows. J. Anim. Sci. 83:557-564.

Krawczyk, C. M., T. Holowka, J. Sun, J. Blagih, E. Amiel, R. J. DeBerardinis, J. R. Cross, E. Jung, C. B. Thompson, R. G. Jones, and E. J. Pearce. 2010. Toll-like receptor-induced changes in glycolytic metabolism regulate dendritic cell activation. Blood 115:47424749 .

Malide, D., T. M. Davies-Hill, M. Levine, and I. A. Simpson. 1998. Distinct localization of GLUT- $1,-3$, and -5 in human monocytederived macrophages: Effects of cell activation. Am. J. Physiol. 274:E516-E526.

Maratou, E., G. Dimitriadis, A. Kollias, E. Boutati, V. Lambadiari, P. Mitrou, and S. A. Raptis. 2007. Glucose transporter expression on the plasma membrane of resting and activated white blood cells. Eur. J. Clin. Invest. 37:282-290.

Newsholme, P., S. Gordon, and E. A. Newsholme. 1987. Rates of utilization and fates of glucose, glutamine, pyruvate, fatty acids and ketone bodies by mouse macrophages. Biochem. J. 242:631-636.
O'Boyle, N. J., G. A. Contreras, S. A. Mattmiller, and L. M. Sordillo. 2012. Changes in glucose transporter expression in monocytes of periparturient dairy cows. J. Dairy Sci. 95:5709-5719.

Ohtsuka, H., C. Watanabe, M. Kohiruimaki, T. Ando, D. Watanabe, M. Masui, T. Hayashi, R. Abe, M. Koiwa, S. Sato, and S. Kawamura. 2006. Comparison of two different nutritive conditions against the changes in peripheral blood mononuclear cells of periparturient dairy cows. J. Vet. Med. Sci. 68:1161-1166.

Orlinska, U., and R. C. Newton. 1993. Role of glucose in interleukin-1 beta production by lipopolysaccharide-activated human monocytes. J. Cell. Physiol. 157:201-208.

Ouro, A., L. Arana, P. Gangoiti, I. G. Rivera, M. Ordonez, M. Trueba, R. S. Lankalapalli, R. Bittman, and A. Gomez-Munoz. 2013. Ceramide 1-phosphate stimulates glucose uptake in macrophages. Cell. Signal. 25:786-795.

Palmer, C. S., J. J. Anzinger, J. Zhou, M. Gouillou, A. Landay, A. Jaworowski, J. M. McCune, and S. M. Crowe. 2014. Glucose transporter 1-expressing proinflammatory monocytes are elevated in combination antiretroviral therapy-treated and untreated HIV+ subjects. J. Immunol. 193:5595-5603.

Pithon-Curi, T. C., M. P. De Melo, and R. Curi. 2004. Glucose and glutamine utilization by rat lymphocytes, monocytes and neutrophils in culture: A comparative study. Cell Biochem. Funct. $22: 321-326$.

Rodriguez-Prados, J. C., P. G. Traves, J. Cuenca, D. Rico, J. Aragones, P. Martin-Sanz, M. Cascante, and L. Bosca. 2010. Substrate fate in activated macrophages: A comparison between innate, classic, and alternative activation. J. Immunol. 185:605-614.

Røntved, C. M., J. B. Andersen, J. Dernfalk, and K. L. Ingvartsen. 2005. Effects of diet energy density and milking frequency in early lactation on tumor necrosis factor-alpha responsiveness in dairy cows. Vet. Immunol. Immunopathol. 104:171-181.

Vats, D., L. Mukundan, J. I. Odegaard, L. Zhang, K. L. Smith, C. R. Morel, R. A. Wagner, D. R. Greaves, P. J. Murray, and A. Chawla. 2006. Oxidative metabolism and PGC-1beta attenuate macrophage-mediated inflammation. Cell Metab. 4:13-24.

Wong, S. Y., L. M. Guerdoud, A. Cantin, and D. P. Speert. 1999. Glucose stimulates phagocytosis of unopsonized Pseudomonas aeruginosa by cultivated human alveolar macrophages. Infect. Immun. 67:16-21.

Xu, J., F. Chi, T. Guo, V. Punj, W. N. Lee, S. W. French, and H. Tsukamoto. 2015. NOTCH reprograms mitochondrial metabolism for proinflammatory macrophage activation. J. Clin. Invest. 125:1579-1590.

Zhao, F. Q. 2014. Biology of glucose transport in the mammary gland. J. Mammary Gland Biol. Neoplasia 19:3-17.

Zhao, F. Q., and A. F. Keating. 2007. Functional properties and genomics of glucose transporters. Curr. Genomics 8:113-128. 